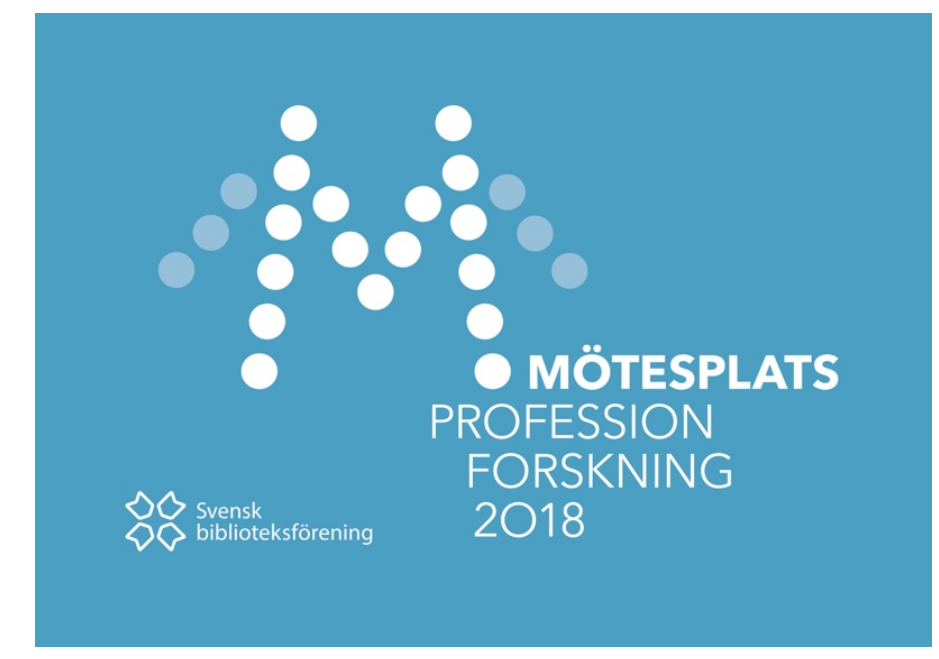

Emma Burman och Wolmar Nyberg Åkerström

Linköpings universitetsbibliotek och Uppsala universitetsbibliotek

emma.burman@liu.se,wolmar@ub.uu.se

\title{
Digital humaniora utmanar biblioteket
}

\section{Introduktion}

Digitalisering av källmaterial och arbetssätt har inneburit nya möjligheter och utmaningar för alla delar av samhället, och inte minst i akademiska sammanhang. Resurser som tidigare enbart funnits tillgängliga i pappersform blir i allt högre utsträckning fritt tillgängliga på Internet, långt utanför bibliotekens väggar, och i format som kan läsas och tolkas av datorprogram och algoritmer.

\subsection{Problemformulering}

För nio år sedan beskrevs digital humaniora (DH) som "the next big thing" och begreppet har senare liknats vid en allegori för framtidens humaniora (Liu, 2012). Idag möter vi som biblioteksanställda begreppet i interaktionen med såväl forskning som utbildning. Och arbetet med att förstå de utmaningar och möjligheter som DH innebär för biblioteket har fortlöpt parallellt i initiativ med olika perspektiv på Linköpings universitetsbibliotek (LiUB) och på Uppsala universitetsbibliotek (UUB).

Syftet med den här artikeln är att ge en intressant och nyanserad bild av de utmaningar och möjligheter vi ser framför oss. Och vi har sökt erfarenheter från kollegor i Norden och i andra delar av världen för att svara till frågeställningarna:

- Hur kan vi som bibliotek förhålla oss till begreppet DH?

- Hur kan vi stötta forskning och utbildning med inslag av DH?

\subsection{Linköpings universitetsbibliotek (LiUB)}

LiUB består av tre campusbibliotek förlagda till Linköping och Norrköping, samt Byggmästare John Matssons bibliotek vilket är förlagt till Lidingö i Stockholm. Det senare biblioteket ingår inte här.

Under det senaste året har ett uppstartsprojekt i forma av ett kombinerat Digitalt Lab och Makerspace - DigiMaker, pågått. Under hösten 2018 invigs verksamheten och kommer att 
erbjuda introduktioner och workshops inom digitalt berättande, 3D/CAD och Virtual Reality, samt ingå med filmskapande i en kurs på masternivå. Efterfrågan på detta ser vi framför allt komma på studentnivå, eller för studenter från lärarhåll.

På forskarsidan har följande hittills gjorts:

- Stöttar och deltar i en förstudie om simulerade klassrum ${ }^{1}$,

- söker och skapar kontakter med intresserade forskare, diskuterar behov, önskemål och möjligheter,

- intern kompetensutveckling.

Utifrån de samtal vi haft med intresserade forskare framgår behoven av en lokal, en samarbetsyta och kompetens klart. Man är mycket positiv till bibliotekets vilja att bygga upp något och nämner vikten av en ämnesöverskridande och experimentell miljö, och att biblioteket kan erbjuda teknisk support. Det har i hos de kontakter vi har funnits tankar och planera att bygga upp en lab-miljö inom universitetet av en av de vidtalade forskarna, vilket följer den europeiska trenden (Zhang et.al., 2015) med DH-miljöer utan bibliotekskoppling, men man är å andra sidan mycket positiv och intresserad av att bidra till att det istället byggs upp inom bibliotekets ramar.

\subsection{Uppsala universitetsbibliotek (UUB)}

UUB grundades på 1600-talet och tillhandahåller informationsresurser för forskning, undervisning och lärande vid Uppsala universitetet och samlingarna omfattar en betydande mängd specialsamlingar och kulturarvsmaterial. Idag är verksamheten indelad i fyra avdelningar med olika arbetsområden och cirka 200 anställda med kompetens inom flera yrkeskategorier. Det fysiska biblioteket är fördelat över 11 platser i Uppsala och i Visby.

Förutsättningarna för verksamheten förändras med åren. Just nu satsar UUB på att utveckla och tillgängliggöra samlingar på nya sätt för att möta dagens utmaningar. Och den här artikeln bygger på delvis på underlag och erfarenheter från satsningar på digitalisering, labbmiljöer i biblioteken, och stöd och service för DH.

Under 2014 lanserades Alvin som en plattform för långsiktigt bevarande och tillgängliggörande av digitaliserade samlingar och digitalt kulturarvsmaterial. Alvin innehåller poster och digitala filer för arkiv, bilder, kartor, böcker/handskrifter, föremål, ljudinspelningar, musikalier, video, programvara och musikalier. Idag finns drygt 60 tusen poster och 340 tusen fritt tillgängliga filer som representerar en växande del av UUB:s digitaliserade samlingar.

Under 2017 etablerades Ekonomikum Digital Library Lab och Ångström Visualisation Lab i anslutning två av universitetets campusområden. I labben finns programvara och utrustning för datahantering, visualisering och mediaproduktion. Biblioteket organiserar ett flertal workshops, seminarier och andra evenemang tillsammans med universitetets forskare, studenter och lärare.

Under våren 2018 rekryterades bibliotekarier med expertis inom digitala metoder och samtidigt genomfördes en förstudie med fokus på stöd och service för $\mathrm{DH}$.

\footnotetext{
${ }^{1}$ http://www.mynewsdesk.com/se/hogskolanvast/pressreleases/goer-virtuell-praktik-saa-att-blivande-laerareundervisar-effektivare-2299695
} 


\section{Genomförande}

Underlaget till den här artikeln producerades som en del av omvärldsanalysen i olika initiativ på LiUB och UUB. Vi valde ett deskriptivt angreppsätt när vi sammanställt resultaten eftersom det är lämpligt och vanligt förekommande vid den här typen av generella undersökningar (Ejvegård, 1996). Resultaten sammanfattar observationer och erfarenheter från:

- bakgrundsinläsning kring $\mathrm{DH}$ och bibliotek,

- studiebesök på 12 universitet och 5 nationella bibliotek i USA och i Danmark,

- en mejlenkät som skickats till 12 nordiska universitetsbibliotek.

\subsection{Bakgrundsinläsning}

Bakgrundinläsningen baserades på ett informellt och löpande och urval av källor i samband med att vi sökt svar på frågor som dykt upp under arbetets gång. Vi har bland annat hittat och valt källor med hjälp av

- Tips från kollegor och forskare

- Biblioteksorganisationer (Biblioteksföreningen, Liber och IFLA)

- Bakgrundsmaterial från tidigare satsningar

- Inläsning inför studiebesök

- Nyckelordssökningar i bibliotekskataloger och tidskrifter

\subsection{Studiebesök}

Studiebesöken finansierades av ett resestipendium på UUB och besöken valdes ut för att biblioteken framgångsrikt bedrivit verksamhet med koppling till $\mathrm{DH}$ och digitala metoder. Besöken avgränsades till 12 universitet och 5 nationella bibliotek i USA och i Danmark för att resan skulle vara genomförbar, att det funnits lämpliga kontaktvägar, och att det funnits intresse av professionellt utbyte. Studiebesöken genomfördes under hösten-vintern 2016 och våren 2018.

Uppläggen för studiebesöken anpassades efter bibliotekens respektive förutsättningar och dokumenterades i form av foton och enkla dagboksanteckningar. Inför besöken formulerades ett par frågeställningar i dialog med personal från olika delar av verksamheten på UUB. Uppläggen omfattade

- Intervjuer med personal och användare,

- deltagande som observatör i olika aktiviteter och möten,

- inventering av platser, marknadsföring och informationsmaterial.

Planerade och genomförda besök

USA, september 2016

- Yale University

- New York Public Library

- Smithsonian Institute

- Library of Congress

- University of Maryland

- George Mason University

- Folger Shakespeare Library

- University of Virginia

- Duke University

- University of North Carolina at Chapel Hill

- North Carolina State University
- Northeastern University

- Digital Public Library of America

Danmark, december 2016

- Köpenhamns universitet

USA, januari-februari 2018

- Northeastern University

- Yale University

- Harvard University

- Tufts Universit

- Boston University 


\subsection{Mejlenkät}

Inför enkäten valdes 12 nordiska universitetsbibliotek. Strategin för urvalet var att biblioteken skulle uppfylla ett eller flera kriterier i syfte att ha något gemensamt med LiUB; att det var verksamt vid ett av de större universiteten i respektive land, att universitetet bestod av flera fakulteter, eller bedrev utbildning inom Humaniora, Medicin och hälsa, och Teknik/Naturvetenskap.

Enkäten, vars syfte var att få en inblick i vad som hänt och är på gång vid andra universitetsbibliotek, bestod i fyra öppna frågor som mejlades till respektive bibliotek:

1. Hur ligger ni till när det gäller Digital Humaniora?

2. Vad har ni gjort?

3. Hur tänker ni framåt?

4. Vad ser ni för möjligheter och utmaningar?

Ungefär två veckor efter att det första mejlet skickades, utgick ett påminnelsemejl till de bibliotek som ännu inte svarat. I de fall ytterligare relevant mejladress fanns skickades påminnelsen även till denna.

Svaren sorterades inledningsvis i kategorierna " $\mathrm{DH}$ " och "Ej $\mathrm{DH}$ ", då det tidigt stod klart att biblioteket inte alltid var universitetets hemvist för DH-arbete. Bearbetningen går in linje med deskriptiv metod, där resultat sorteras och kategoriseras (Ejvegård, 1996). I analysen ingår endast biblioteken som kategoriserades som " $\mathrm{DH}^{\text {". }}$

\section{Resultat}

\subsection{Bakgrundsinläsning}

\subsubsection{Digital Humaniora i allmänhet}

Burdick (2012) skriver att DH uppmuntrar nya sätt att forska inom humaniora och att en möjlig effekt är att gamla gränser suddas ut då nya samarbeten mellan närliggande ämnen och områden uppstår. Det exploderande utbudet med datorer, mobila enheter och kommunikationskanaler har inneburit nya möjligheter att utveckla och dela kunskap oberoende av var i världen man befinner sig (Nyberg, 2014). Vidare kan resultatet av mötet mellan digitala metoder, teknologier och humaniora bli en breddning och förstärkning av humanistisk forskning med ökad tillgänglighet både inom och utanför akademiska sammanhang som följd (Burdick, 2012). Liknande definitioner ger Drucker et.al. (2013) och Raffaghelli et.al. (2016) vilka beskriver DH som en korsning mellan humaniora och digitala teknologier.

Svensson (2010) definierar Centra för Digital Humaniora som rummet eller tillfället där ny kunskap uppstår/uppnås inom humaniora, med digitala metoder, media och teknik.

\subsubsection{Bibliotekets roll i Digital Humaniora}

DH har inneburit att de källmaterial och dataformat som forskare inom humaniora haft behov av har fått en ny karaktär och det har t.ex. blivit möjligt att studera mycket större samlingar av fotografier och text än tidigare (Liu, 2012). Att DH är ett komplext begrepp och att förutsättningarna snabbt förändras med ny teknik innebär att biblioteken behöver utveckla beredskap för att möta dagens och framtidens behov (Sula, 2013).

Svensson (2010) beskriver biblioteket som en form av laboratorium för humanistisk forskning och att kunskaper i samlingsuppbyggnad, informationsvetenskap och IT gör biblioteken 
till en naturlig och viktig infrastruktur för DH. Zhang et al (2015) som studerat hur informationsspecialister kan bidra i DH-satsningar understryker dessutom expertis inom lagring och tillgängliggörande, publicering, söktjänster, undervisning och innovation. Även Green (2014) som gjort en fallstudie kring DH på fem bibliotek i USA redovisar att samarbetet med biblioteket är en förutsättning för ett optimalt genomfört arbete. Wong (2016) påtalar styrkan i att samla experter och specialister från olika områden som en del av att ta $\mathrm{DH}$ till dess fulla potential.

\subsection{Studiebesök}

Erfarenheterna från studiebesöken visar att biblioteken har bidragit till att utveckla sin roll och nya tjänster i en skärningspunkt mellan informationsvetenskap, traditionell biblioteksservice och IT. Informationsspecialister, programmerare, designers och teknikkunniga kompletterar varandra i biblioteket och man arbetar tillsammans med studenter, lärare och experter från olika forskningsområden för att möta utbildningens och forskningens behov. Biblioteken tillhandahåller resurser och service kring

- Samlingar - Skräddarsydda databaser/söksystem, digitala arkiv, databaslistor, digitalt födda källor, digitaliseringstjänster och kulturarvsdata

- Integrerad stödverksamhet - Datahantering, data literacy, dataanalysverktyg, visualisering, web scraping och grundläggande programmering

- Publicering och samverkan - Digitala utställningar, databaser, crowd sourcing, öppna forskningsdata och öppen källkod

- Arbetsplatser och labbmiljöer - Programvara, utrustning, inspiration och mötesplatser som möjliggör nya perspektiv och arbetssätt

Det finns synergieffekter i bibliotekens engagemang i DH som bidrar till kompetensutveckling av biblioteksverksamheten i övrigt. Det är samtidigt en utmaning att positionera och dimensionera platser och service i förhållande till användarnas behov/förväntningar och uppdraget från bibliotekens finansiärer.

Återkommande teman för stöd till DH är t.ex. GIS, transkribering, dataanalys för texter och bilder, visualisering, digital storytelling, multimedia och interaktiva webbplatser. 
Strategisk ledning

- Ofta forskare/forskarbakgrund med en fot i forskningen/ utbildningen

- Biblioteken kompletterar existerande labb/centra i forskningen/utbildningen

- Skapar utrymme för och förankrar försöksverksamhet

Operativ ledning

- Bibliotekarie eller expert inom området som verksamheten fokuserar på

- Arbetar metodisk med UX/användarfokus - t.ex. Learning Space Toolkit

- Håller ihop samarbeten, prioriteringar och förvaltning

Arbetsgrupp

- Bibliotekarier och andra informationsexperter

- Experter med särskild profession/kompetens - ofta disputerade, ibland bibliotekarier

- Projektanknutna forskare och studenter

- Forskarstudent-personal / studentpersonal

\section{Samarbeten}

- Anlitar/bjuder in experter, studenter och forskare från institutionerna

- Delar resurser med andra bibliotek kursmaterial, källkod, expertis

- Utbyte med e-lärande, pedagogik och statistik/datahantering

- Nära IT, drift och förvaltning

Aktiviteter

- Öppna evenemang

- Workshops

- Helpdesk

- Drop-in-tider

- Individuell handledning/rådgivning

- Kurser

- Coachning

- Medverka i interna/externa projekt

- Självservice på webben / Manualer

- Systemutveckling

- Förvaltning

- Drift och underhåll 


\subsection{Mejlenkät}

Bakgrundsläsningen kombinerat med enkätsvaren resulterade i fyra kategoriseringar av svaren. Kategorierna är inspirerade från Zhang et al (2015) som menar att bibliotekens förhållning till DH åtminstone kan identifieras i två olika spår - dess positionering och aktiviteter kopplat till DH:

- Aktiva - Svaren visade att biblioteket aktivt arbetade med DH.

- Indirekt aktiva - Biblioteket angav att de inte arbetade med DH men svaren vittnade om aktiviteter som kan vara ett stöd inom ramen för $\mathrm{DH}$, exempelvis:

E-science är ett viktigt fokusområde här, och big data är relevant inom flera projekt. Biblioteket erbjuder också support kring hanteringen av forskningsdata.

- DH positionering - Svaren visar hur biblioteket positionerar sig inom $\mathrm{DH}$. Det kan vara att vara medlemmar i ett nätverk, samarbetar med ett DH-projekt på universitetsnivå eller på annat sätt är delaktiga i ett samarbete kring $\mathrm{DH}$, exempelvis:

Vi har nyligen haft en dialog med initiativtagarna till forskningsområdet inom $D H$, för att se hur biblioteket kan stödja och involveras i projektet.

Det har varit diskussioner kring att ansluta biblioteket till ett EU-nätverk eller -projekt.

- Ej aktiva - Innefattar de bibliotek som svarar att de inte arbetar med DH, och inget i svaren indikerar aktivitet.

- Ingen respons - Bibliotek som trots påminnelse inte svarar på enkäten alls. Respons uteblev från de tre biblioteken i Finland, samt från ett av de norska biblioteken.

Tabell 1. Kategoriseringar av enkätsvar fördelat över land. Det bibliotek som svarat på enkäten representeras av landets initialbokstav följt av en siffra (1-3).

\begin{tabular}{llllll}
\hline Land & Aktiva & Indirekt aktiva & DH positionering & Ej aktiva & Ingen respons \\
\hline Sverige & $\mathrm{S}: 1$ & $\mathrm{~S}: 2$ & $\mathrm{~S}: 1$ & $\mathrm{~S}: 3$ & \\
Norge & $\mathrm{N}: 1, \mathrm{~N}: 3$ & & $\mathrm{~N}: 1, \mathrm{~N}: 3$ & & $\mathrm{~N}: 2$ \\
Finland & & & & & $\mathrm{F}: 1, \mathrm{~F}: 2, \mathrm{~F}: 3$ \\
Danmark & $\mathrm{D}: 1, \mathrm{D}: 3$ & $\mathrm{D}: 1, \mathrm{D}: 2$ & $\mathrm{D}: 3$ & & \\
\hline Totalt & 5 & 3 & 4 & 1 & 4 \\
\hline
\end{tabular}

Flera av svaren inom kategorierna Aktiva, Indirekt aktiva och Ej aktiva hänvisade till universitetsenheter utanför biblioteket, vilket indikerade att biblioteken inte alltid var den naturliga hemvisten för DH-relaterat arbete.

Av de bibliotek som angett att de aktivt arbetade med DH framgick att de tillfrågade biblioteken befinner sig i ett tidigt skede:

Hittills tycker vi att det varit lite svårt och spretigt. Vi vill gärna vara med i detta spännande fält som växer fram. En utmaning kan vara att ha rätt kompetens på UB för nya områden som detta! 
När det kommer till hur de tillfrågade, och på något sätt aktiva, biblioteken positionerar sig förefaller det mestadels ske i en samarbetskontext, antingen med forskare eller med nätverk.

\section{Diskussion}

\subsection{Hur kan vi som bibliotek förhålla oss till begreppet $D H$ ?}

Begreppet digital humaniora är både omdiskuterat och föränderligt, vilket gör det svårt att ringa in med en kortfattad och entydig definition. Även om vi skulle välja att se på begreppet som en korsning mellan humaniora och digitala teknologier är definitionen i bästa fall vag och i värsta fall en källa till missförstånd. Om DH visar sig vara en indikator för framtidens humanistiska forskning, som Liu (2012) begrundar, står det i alla fall klart att fler forskare t.ex. kommer att

- arbeta med digitalt källmaterial av större omfattning och komplexitet

- väva in teknologi och programmering i sin forskning

- använda nya mediatyper och kanaler för att nå ut

- medverka i interdisciplinära arbetsgrupper

Vi kan alltså förhålla oss till DH utifrån forskningens och utbildningens förändrade och kommande behov. Bakgrundinläsningen beskriver att biblioteket kan fylla flera viktiga funktioner som stöd till forskning inom DH och det bekräftar också studiebesöken. Frågan är inte om utan när och hur universitetsbiblioteket behöver ta höjd för att utveckla verksamheten.

Det finns en rad andra besläktade begrepp som i viss mån definierar en trend av ökande datorisering och teknologisk utvecklingen med ordet "digitalt" som förled. Vi är bekanta med det digitala biblioteket, digital publicering och digitalt kulturarv och vi kan föreställa oss $\mathrm{DH}$ och digital samhällsvetenskap som en del av ett bredare digital scholarship ${ }^{2}$. DH skulle också kunna ha avsmalnande specialiseringar som digital historia och digital arkeologi. Vi tänker oss att flera forskningsområden och samhället i stort kommer att ställas inför liknande utmaningar och att en stödverksamhet för DH kan generaliseras till fler vetenskapsområden.

Som en slutsats av den här delen av arbetet har vi formulerat ett par generella medskick:

- Formulera en strategisk riktning och samarbeten som positionerar verksamheten i en nära relation till pågående forskning och utbildning med inslag av $\mathrm{DH}$.

- Engagera personal med tekniska/metodmässiga färdigheter, ämneskunskaper och projektkompetens i kombination med utpräglad förmåga att utvecklas i sitt arbete och att samarbeta. Lewis et al (2015) sammanfattar såhär:

[...] our interviews revealed in particular the importance of collaborative competencies, reflecting the ways in which digital scholarship typically takes place in teams dependent on diverse expertise. Since digital scholarship often involves developing new methods, tools, and theoretical approaches, successful digital scholars usually exhibit creativity, curiosity, and an enthusiasm for learning, which we term learning mindsets. Some level of general domain knowledge is

\footnotetext{
2 McKenzie et al (2016) beskriver digital scholarship i termer av akademisk forskning och lärande som möjliggörs av digitala metoder av olika slag.
} 
useful so that team members can understand the research questions they are pursuing, while researchers draw upon methodological competencies (such as data science and GIS) and technical skills (such as database design and programming) to carry out their research. Finally, managerial skills-particularly project management-are needed to ensure that projects are completed.

- Säkra tekniska förutsättningar som tillgång till programvara, lagringsutrymme, datorer, serverar/webbplats och övrig utrustning.

- Sätt ramar för arbetsuppgifter och aktiviteter men lämna utrymme för personalen att utveckla sitt uppdrag genom försöksverksamhet.

\subsection{Hur kan vi stötta forskning och utbildning med inslag av DH?}

Resultatet från studiebesöken ger en inblick i vilken form av stöd biblioteken erbjuder och hur verksamheten är organiserad (sid. 5). Våra intryck är att personalen och samarbeten har haft en avgörande roll i att forma verksamheten utifrån lokala förutsättningar, vilket bekräftas av Lewis et al (2015). Och vi instämmer även med Wong (2016) och Green (2014) i att det förefaller naturligt och effektivt att etablera täta samarbeten med forskare, forskarstudenter och andra experter utanför biblioteket.

\subsubsection{Sätt ramar för arbetsuppgifter och aktiviteter}

Det finns flera frågor biblioteken behöver ta ställning till i ett relativt tidigt skede av sitt arbete med $\mathrm{DH}$;

- Är bibliotekets stöd till DH ett arbete som fokuserar på att utveckla samlingar och förbättra söksystem för att möta nya behov?

- Är bibliotekets stöd till DH ett servicearbete där man utför tjänster för användarna?

- Är bibliotekets stöd till DH ett konsultativt stöd där man hjälper användarna att själva komma igång eller lösa sina problem?

- Vilken är målgruppen? Studenter eller forskare, eller båda grupperna?

Ställningstagandet behöver inte innebära att det ena utesluter det andra - men det är frågor som bör diskuteras.

\subsubsection{Engagera personal}

Utifrån resultatet av enkäten samt erfarenheter från studiebesöken kan vi se att intern kompetens är relevant. Det handlar om att utröna vilka kompetenser som redan finns internt, samt att höja kompetensen inom relevanta områden, såsom kring öppna data, nya medier o.s.v., men det handlar också om att väcka den interna medvetenheten om vad DH innebär och hur bibliotekspersonalen i sitt dagliga arbete kan fånga upp behov och förmedla kontakt där biblioteket når ut till nya partners.

Att öka kompetensen generellt internt kan också gynna att flera synergieffekter uppnås då högre kompetens och kunskapen om digitala metoder inte bara bidrar till bättre möjligheter att förmedla och ge stöd i dessa - utan även kan berika bibliotekets arbete med samlingar, söktjänster och utvecklingsarbete.

Följande är ett par exempel på potentiella utmaningar där biblioteket skulle kunna erbjuda ett kvalificerat stöd, beroende på vilken kompetens som finns i och i anslutning till organisationen. 
- Litteraturstudier och kvalitativ dataanalys med t.ex. NVivo

- Geo-dataresurser och GIS med t.ex. QGIS och ArcGIS

- Datahantering, textanalys/nätverksanalys och datavisualiseringar med t.ex. Excel, NVivo, Jupyter, RStudio, Tableau

- Multimedia och 3D-modellering med t.ex. SketchUp Pro, Sketchfab

- Digitala utställningar och kulturarvspedagogik med t.ex. Omeka-S, Alvin

- Avtal, villkor och lämpliga arbetssätt för att använda bibliotekets databaser och resurser i stora utsökningar och via API:er

- Publicering och arkivering av webbsidor, forskningsmaterial och källkod i digitala arkiv med t.ex. DiVA, Alvin

- Maker-aktiviteter, Design Thinking och immersiv teknik med t.ex. 3D-skrivare, VR-utrustning och pekskärmar

- Publiceringsstrategier och kanaler för crowdsourcing, källkod och öppna data med t.ex. GitHub, Zooniverse, FromThePage

- Transkribering eller manuell datainmatning med t.ex. Transkribus, NVivo, Scripto

- Bildanalys och uppmärkning för att underlätta sökningar i bildsamlingar med t.ex. ABBY FineReader, Tropy

\subsubsection{Arbetsplatser och labbmiljöer}

Ett alternativ kan vara att knyta verksamheten till en fysisk plats för samarbeten och möten över gränserna mellan olika forskningsområden och forskargrupper - där biblioteket står för infrastrukturen samt kan ge stöd i och introducera digitala metoder och arbetssätt, där en forskare kan delge andra forskare sina erfarenheter.

I kombination med detta kan en digital plattform byggas upp som kan innehålla digitala resurser, introduktioner eller instruktioner, litteraturhänvisningar och relevanta länkar m.m.

Öppna och riktade workshops där en eller flera digitala metoder demonstreras och kan testas, föreläsningar av olika aktörer, kan bjuda in till ett möte mellan biblioteket och forskarna där forskarna får en inblick i vad biblioteket kan erbjuda, och biblioteket kan få ta del av forskarnas vardag och behov.

Dialogen mellan biblioteket och forskarna är avgörande för att biblioteket ska få bra exempel att jobba med och sprida (storytelling) för att utveckla verksamheten och nå ut.

\subsubsection{Nätverk och samarbeten mellan organisationer}

Samarbete kan och bör inte bara begränsas till att ske inom det egna lärosätet - utbredd infrastruktur DH är relativt nyetablerat inom biblioteksvärlden och samarbeten med andra lärosäten kan på många sätt vara berikande. Under 2018 har ett nationellt samarbete mellan Uppsala UB, Linköpings UB, UB vid Luleå Tekniska Universitet och Umeå UB börjat växa fram och ta form. Redan efter en första träff stod det klart att det är stimulerande och utvecklande att ta del av varandras erfarenheter, kunskaper och verksamheter. 


\section{Käll- och litteraturförteckning}

Burdick, A. (2012). Digital humanities. Cambridge: MIT Press.

Drucker, J., Kim, D., Salehian, I. \& Bushong, A. (2013). Introduction to Digital Humanities : Concepts, Methods, and Tutorials for Students and Instructors. Online. Hämtad februari 2017 från: http://dh101.humanities.ucla.edu/wpcontent/uploads/2014/09/IntroductionToDigitalHumanities_Textbook.pdf.

Ejvegård, R. (1996). Vetenskaplig metod. 2., [rev.] upp. Lund: Studentlitteratur.

Green, Harriett. E. (2014). Facilitating Communities of Practice in Digital Humanities: Librarian Collaborations for Research and Training in Text Encoding. The Library Quarterly 84, no. 2 (April 2014): 219-234. https://doi.org/10.1086/675332

Lewis, Vivian et al. (2015). Building Expertise to Support Digital Scholarship: A Global Perspective. CLIR pub 168. Washington: CLIR. Hämtad från, https://www.clir.org/pubs/reports/pub168/

Liu, Alan. (2012). The state of the digital humanities: A report and a critique. Arts and Humanities in Higher Education, 11(1-2), 8-41. https://doi.org/10.1177/1474022211427364

McKenzie, Alison. \& Martin, Lindsey. (Ed.). (2016). Developing Digital Scholarship: emerging practices in academic libraries. London: Facet Publishing.

Nyberg, Kenneth. (2014). Digital humanities: definitions and debates. In K. Nyberg \& J. Parland-von Essen (Eds.), History in a digital world. Hämtad från, https://digihist.files.wordpress.com/2014/05/hdv_v1_0_1.pdf .

Raffaghelli, Juliana E., Cucchiara, Stefania, Manganello, Flavio \& Persico, Donatella. (2016). Different views on Digital Scholarship: separate worlds or cohesive research field? Research in Learning Technology, Vol. 24. https://doi.org/10.3402/rlt.v24.32036

Sula, Chris Alen. (2013). Digital Humanities and Libraries: A Conceptual Model. Journal of Library Administration. Vol. 53 (1), s. 10-26. https://doi.org/10.1080/01930826.2013.756680

Svensson, Patrik. (2009). Humanities Computing as Digital Humanities. Digital Humanities Quarterly. Vol. 3 (3). Hämtad februari 2017 från, http://digitalhumanities.org/dhq/vol/3/3/000065/000065.html

Svensson, Patrik. (2010). The landsacape of Digital Humanities. Digital Humanities Quarterly, 4(1). Hämtad mars 2017 från, http://digitalhumanities.org/dhq/vol/4/1/000080/000080.html.

Wong, Shun Han Rebekah. (2016). Digital humanities: What can libraries offer? Portal, 16(4), 669-690. https://doi.org/10.1353/pla.2016.0046

Zhang, Ying, Liu, Shu, \& Mathews, Emilee. (2015). Convergence of digital humanities and digital libraries. Library Management, 36(4-5), 362-377. https://doi.org/10.1108/LM-09-2014-0116 